Research Article

\title{
Experimental Investigation on the Load-Carrying Capacity of Steel-to-Laminated Bamboo Dowel Connection I: Single Fastener with Slotted-In Steel Plate under Tension
}

\author{
Zhaoyan Cui ${ }^{D},{ }^{1}$ Liuhui Tu, ${ }^{2}$ Ming Xu ${ }^{D},{ }^{2}$ Zhongfan Chen, ${ }^{2}$ and Qingfeng $X u^{3}$ \\ ${ }^{1}$ National Engineering Research Center of Biomaterials, Nanjing Forestry University, Nanjing 210037, China \\ ${ }^{2}$ Key Laboratory of Concrete and Prestressed Concrete Structures of Ministry of Education, Southeast University, \\ 02, Southeast University Road, Nanjing 211189, China \\ ${ }^{3}$ Shanghai Key Laboratory of Engineering Structure Safety, SRIBS, Shanghai 200032, China
}

Correspondence should be addressed to Ming Xu; xuming@seu.edu.cn

Received 2 November 2020; Revised 22 December 2020; Accepted 31 January 2021; Published 16 February 2021

Academic Editor: Filippo Ubertini

Copyright (C) 2021 Zhaoyan Cui et al. This is an open access article distributed under the Creative Commons Attribution License, which permits unrestricted use, distribution, and reproduction in any medium, provided the original work is properly cited.

\begin{abstract}
The dowel-type connection is widely applied in timber and bamboo structures. It is ambiguous regarding the calculation method of engineered bamboo connections completely referred to the timber design codes. The steel-to-laminated bamboo dowel connections with slotted-in steel plate tests were conducted to investigate the mechanical performance under tension based on the ASTM-D5652-15. The effects of the thickness, dowel diameter, and end distance on the yield load, ultimate load, initial stiffness, and ductility of the connections were studied. The difference in the yield load for different end distance is negligible. With the same thickness of the connections, the lower the thickness to dowel diameter, the larger the load-carrying capacity. The three typical yield modes and corresponding load-displacement curves of the connections are observed. By considering the rigid-plastic model, the theoretical equation for the connections is proposed and proven to fit well with the experimental results. It presents a better prediction for the load-carrying capacity of steel-to-laminated bamboo dowel connections with slotted-in steel plate.
\end{abstract}

\section{Introduction}

Due to the advantages of a simple manufacturing process, low adhesive content, and beautiful surface, laminated bamboo has a broad prospect as an engineered material in the construction industry $[1,2]$. Compared with other biological structural materials, the laminated bamboo has higher tensile strength and stiffness with less variability [1], meaning that, for construction purposes, it would be a better choice than the others.

For the engineered structures, the reliability of the connections is the key to the structural design. The connection performance of laminated bamboo could directly affect the strength, life expectations, and robustness of the structure, making the relevant research extremely important. The dowel connection of the timber and bamboo structure can be divided into single-shear connection and double-shear connection from the number of shears faces of each dowel. The multishear connections can be divided into a wood-to-wood connection and a steel-to-wood connection from the different materials of the connected main and side materials, and the steel-to-wood connection includes a steel splint connection and a steel filler connection. The simple form and reliable transmission of force make the steel-towood connection the most important form of connections in the modern timber structures, especially those dowel-type connections with slotted-in steel plates for having no steel plate coverage and good aesthetics; and the occurrence of cracks can be easily observed to avoid potential safety hazards [3].

Researchers have explored the calculation theories and methods of wood bolt connection for years. The European yield theory was originated from Johansen [4] theory of timber connection, which set the foundation for Eurocode 5 
[5]. In the United States, the design method has been changed from empirical design to method based on the yield theory since 1991. Several factors, such as the dowel diameter, the thickness to diameter ratio, and the end distance have been investigated to study the possible effect on the load-carrying capacity of the connection. Daudeville et al. [6] carried out the dowel-bearing test on the wood, indicating that the dowel diameter has an influence on the bearing strength. In a certain range, it has a positive correlation with the dowel-bearing strength, and the result is consistent with the European wood structure design specification. Solitis et al. [7] proposed the concept of thicknessto-diameter ratio in 1987 and believed that, with the same dowel diameter, the greater the thickness of the bolted joint of wood, the better the ductility. Cesar [8] pointed out in the study that when the dowel end distance to diameter ratio is less than 4, the brittle fracture is easy to occur. Doyle [9] found that an increase in the spacing of the bolts within a certain range helps to enhance the bearing capacity of the joints. The requirements on these bolted constructions directly affect the form of damage to the joints. The loading direction has also been found to have a significant effect on the performance of the connection. The failure modes of the timber loaded parallel and perpendicular to the grain are significantly different. Patel and Hindman [10] studied the bearing properties of the bolted joints in the transverse direction and found that the failure mode is related to the fracture toughness of the wood. In addition, moisture content [11] and temperature can affect the load-carrying capacity.

At present, the existing equations of the steel-to-wood connection in the national design codes and standards focus on different failure modes: Eurocode 5: design of timber structures evaluates the bearing capacity of the connection with the thickness of the side members, the dowel-bearing capacity of the material, and the diameter of the dowel. The minimum value of predictions under each failure mode is taken as the calculation result to predict the bearing capacity of the connection. Similar methods have been applied in the National Design Specification for Wood Construction in the US [12] and the Canadian Standard [13].

Although the bamboo material shares great similarities with wood at the aspect of physical and mechanical properties, the difference between the two materials is not negligible. There are relatively few studies on the engineered bamboo material. Cui et al. [14] tested the bearing capacity of bolted steel-bamboo scrimber-steel connections and found that Eurocode 5 had better prediction accuracy. Hover [15] conducted an experimental study on the bolt connection of the laminated bamboo loaded parallel to the grain and analyzed its failure mechanism and bearing capacity. In general, the research on the bearing performance of laminated bamboo connections is still scarce at home and abroad, and further exploration is urgently needed.

The purpose of the study is to analyze the load-carrying capacity of the steel-to-laminated bamboo connection loaded parallel to the grain. The dowel diameter, the thickness, and the end distance of the connections have been taken into consideration. The experimental results have been compared with the existing equations, and a more accurate equation for laminated bamboo has been developed based on the analysis in the paper.

\section{Materials and Test Methods}

2.1. Materials. The fabrication process of the raw laminated bamboo material has been described specifically in previous research [16]. Based on the Chinese standard [17], ASTM D143-14 [18], and ASTM D5764-97a [19], the physical and mechanical properties of the laminated bamboo have been tested. The mean values of its air-dry and oven-dry density are $609 \mathrm{~kg} / \mathrm{m}^{3}$ and $592 \mathrm{~kg} / \mathrm{m}^{3}$ with a moisture content of $5.9 \%$. The compressive strength is $59.63 \mathrm{MPa}$ parallel to the grain with the MOE of $12087 \mathrm{MPa}$. The corresponding tensile strength is $104.16 \mathrm{MPa}$ with the MOE of 10820 , and the shear strength is $17.26 \mathrm{MPa}$. The tensile strength of laminated bamboo perpendicular to grain is $3.35 \mathrm{MPa}$. The yield strength of the dowel is $480 \mathrm{MPa}$ and the tensile strength is $600 \mathrm{MPa}$. The length of the unthreaded area in the middle of the screw was not less than $120 \mathrm{~mm}$. The steel plate is Q345 grade steel with a thickness of $10 \mathrm{~mm}$; and the thickness of the groove is $12 \mathrm{~mm}$.

2.2. The Test Specimens and Method. As mentioned before, many factors may influence the bearing capacity of the connections. In this study, the dowel diameter, the thickness, and end distance are selected as reference factors. The test set-up and front and lateral views of the connections are shown in Figure 1. The length of laminated bamboo specimen is $900 \mathrm{~mm}$, and the width is $120 \mathrm{~mm}$. It is noted that the end distances of the connections are $5 D, 6 D, 7 D$, and $8 D$ except that the control group is $7 D$. The detailed parameters of different groups are shown in Table 1. Each test was repeated 3 times. The test method was based on ASTMD5652-15 [20] and was appropriately adjusted in combination with the test conditions. The test was carried out with a 100-ton MTS Fatigue testing machine. As shown in Figures 1(b) and 1(c), 1 denotes the MTS actuator, 2 the fixed device for the steel plate, 3 the steel plate, 4 the displacement transducer support, 5 the dowel, 6 the displacement transducer roof, 7 the fixed device for the specimens, and 8 the MTS ground anchor. After preloading to eliminate the effect of the initial gap and deformation, the specimens were subjected to monotonic uniform loading in the tension direction with displacement control. The loading rate was $1 \mathrm{~mm} / \mathrm{min}$. The loading process stopped when significant damage appeared or the bearing capacity dropped below $80 \%$ of the maximum load. The load of the connections was measured by the test set-up. The displacement was measured by two displacement transducers on both sides.

The average value measured by the two displacement meters was chosen as the relative displacement between the dowel and the laminated bamboo, and the load data are combined to generate the load-displacement curves. A straight line was fit to the initial linear portion of the loaddeformation curve. The line was offset by a deformation equal to $5 \%$ of the fastener diameter. The load at which the 
offset line intersects the load-deformation curve was selected as the yield load, $F_{y}$. The elastic stiffness, $K_{1}$, is calculated by the slope of the initial linear portion of the load-deformation curve. The postyield stiffness, $K_{2}$, is calculated by the tangent of the load-displacement curve through the intersection of the initial linear portion of the load-deformation curve and the horizontal line through the yield load.

\section{Results and Analysis}

3.1. The Failure Modes and Load-Displacement Curves of the Connections. According to the Eurocode yield theory, there are three yield modes for double-shear connections in Figure 2. Mode I represents the case where fasteners do not bend, and wood fibers crushing occurres beneath the dowel without through cracks. Mode II represents the case where fasteners yield in bending at one plastic hinge point per shear plane, with bearing-dominated yield of wood fibers in contact with the fasteners in side member(s), respectively. Mode III represents the case where fasteners yield in bending at two plastic hinge points per shear plane, with the limited localized crushing of wood fibers near the shear plane(s).

As shown in Figure 3, all of the three yield modes of the dowels occur in the connections. When the thickness of side members is small and the thickness to diameter ratio is also small, Mode I is prone to occur, for example, T2-D1-L1. It is mainly because the bending strength of the dowel is larger and the shear strength of the laminated bamboo parallel to grain is lower. But when the thickness to diameter ratio is large enough, Mode III occurs, specimen T1-D2-L1. It is because the bearing zones become larger and dowel bending is restrained. For the other connections, the failure modes belong to Mode II.

The failure modes of side members under the yield mode of one plastic hinge (Mode II) are mainly shear failure and splitting failure and they are accompanied by embedding failure. When the thickness of side members is small, the ductility is lower and the specimen exhibits splitting failure. As the thickness increases, the plastic displacement increases, and the dowel hole is elongated. The specimens exhibit splitting failure and embedding failure. But when the dowel diameter is larger, for example, M14 and M16, the specimens exhibit shear failure and embedding failure. When the end distance of the connections is in the range of $6 D-8 D$, the connections exhibit better ductility and embedding failure. Therefore, the sufficient end distance of the connections is essential in the design of the laminated bamboo connections.

The typical load-displacement curves of the connections are shown in Figure 4. The curves can be divided into a linear branch, a nonlinear branch within and beyond the proportional limit, and falling branch rapidly. The influences of the dowel diameter, thickness, and end distance on the mechanical properties of the connections parallel to grain were analyzed in the paper. As shown in Figure 4(a), with the dowel diameter increasing from $10 \mathrm{~mm}$ to $16 \mathrm{~mm}$, the ultimate load, yield load, and initial stiffness increase gradually. When the dowel diameter is $10 \mathrm{~mm}$, the ultimate displacement is about $20 \mathrm{~mm}$ and it exhibits better ductility.
As the thickness increases, the ultimate load and displacement increase in Figure 4(b). When the thickness is $30 \mathrm{~mm}$, the ultimate load and displacement are too small, just $27.15 \mathrm{kN}$ and $2.49 \mathrm{~mm}$. The ultimate displacement is close in the range of $90-120 \mathrm{~mm}$. The connections have good ductility and the curve change is similar to the same diameter and thickness when the end distance is above $6 D$ as shown in Figure 4(c). Therefore, an end distance of 6 to 8 dowel diameters and a thickness equal to or greater than 7 dowel diameters will provide reasonable results for laminated bamboo connections.

3.2. The Effect of Different Factors. The test results are shown in Table 2. The mean values of a series of measurements of different groups have been collected. The initial stiffness of the connections, $K_{1}$, yield displacement, $\Delta_{\mathrm{y}}$, and yield load, $F_{y}$, were obtained by the $5 \%$ diameter offset method. $\mu$ is the ductility ratio, $\mu=\Delta_{\mathrm{u}} / \Delta_{\mathrm{y}}$. and COV is the coefficient of variation of $F_{u}$. If the displacement at the point of intersection is larger than the ultimate displacement, the ultimate load is defined as the yield load. The ultimate load, $F_{u}$, was obtained as the load-carrying capacity of the connections.

The influences of the dowel diameter, thickness, and end distance on the yield and ultimate load, initial stiffness, and ductility ratio are compared and analyzed in Figure 5. For T1-D1-L1 as the control group, the corresponding yield and ultimate load are $32.33 \mathrm{kN}$ and $50.56 \mathrm{kN}$; and the initial stiffness and ductility ratio are $43.56 \mathrm{kN} / \mathrm{mm}$ and 10.26 . For the dowel diameter, with the diameter increasing from $10 \mathrm{~mm}$ to $16 \mathrm{~mm}$, the yield and ultimate load and the initial stiffness increase gradually in Figure 5(a). But the ductility ratio slightly reduces. It is because the dowel diameter determines the bearing area between the dowel and the bamboo material but the increase of the diameter of the connections could cause the failure mode to change from combined embedding failure and splitting failure to shear failure.

As for the thickness factor, it has the most significant effect on the initial stiffness, ductility ratio, and ultimate load of the connections in Figure 5(b). As the specimen increases from $30 \mathrm{~mm}$ to $120 \mathrm{~mm}$, the ultimate load increases rapidly from $27.15 \mathrm{kN}$ to $50.56 \mathrm{kN}$ and the ductility ratio increases from 1.98 to 10.26. But when the thickness of side members is in the range of $90-120 \mathrm{~mm}$, the thickness variation has no significant effect on yield load. It is mainly because the failure modes are similar, and the yield mode is determined by the compressing buckling of the bamboo fiber, which belongs to the local material property and is independent of the overall size of the specimens.

When the end distance of the connections increases from $5 D$ to $8 D$, the shear area of side members enlarges as well, leading to the ultimate load increasing slightly. There is no obvious correlation between end distance with the yield load and initial stiffness because the yield mode depends on the material properties of the laminated bamboo. The initial stiffness is around $38-45 \mathrm{kN} / \mathrm{mm}$. It is noted that when the end distance is $60 \mathrm{~mm}$, the ductility ratio is very small, just 3.7. It should be avoided in the design of engineered bamboo 


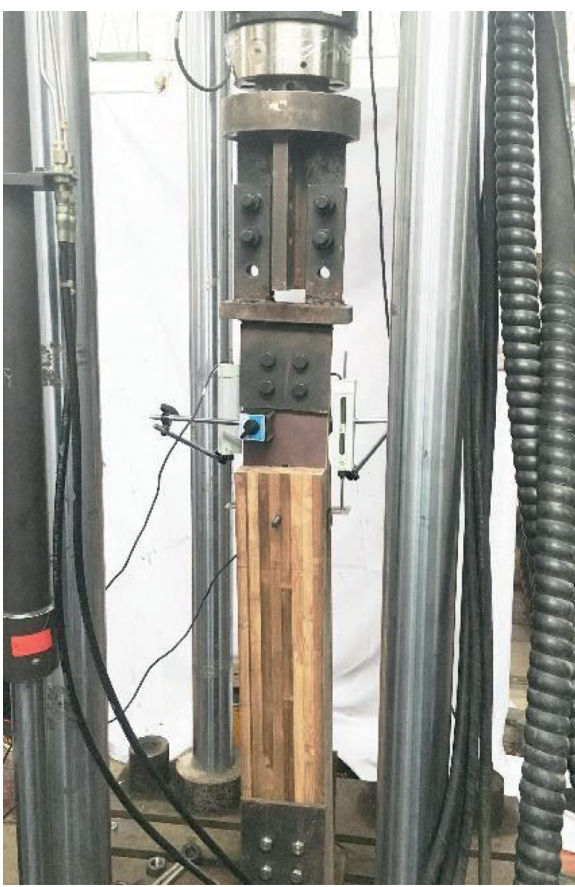

(a)

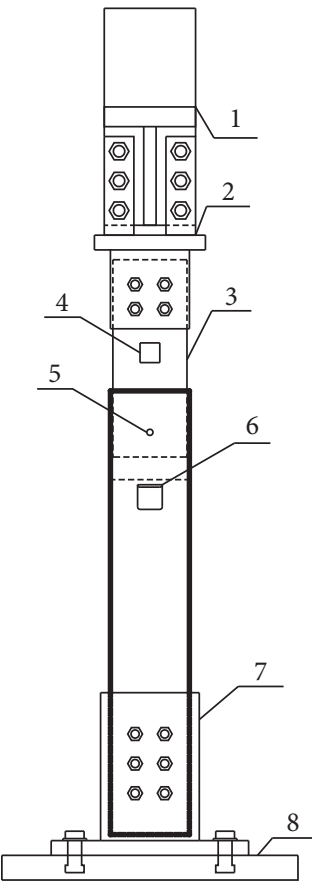

(b)

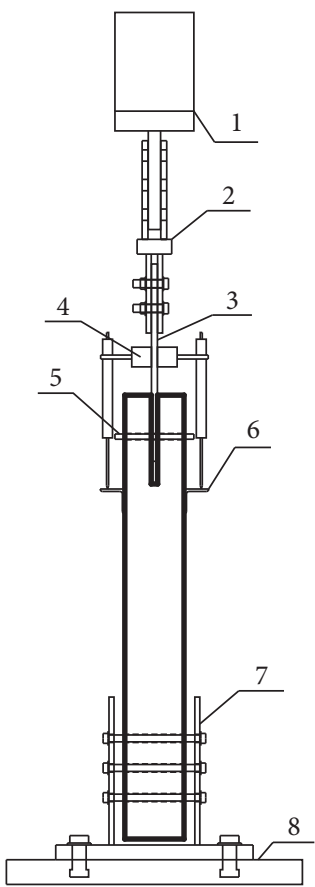

(c)

Figure 1: Test method of the connections. (a) Test set-up. (b) Front view. (c) Lateral view.

TABLE 1: Detailed parameters of different groups parallel to grain.

\begin{tabular}{|c|c|c|c|c|c|}
\hline No. & $t(\mathrm{~mm})$ & $t_{s}(\mathrm{~mm})$ & $D(\mathrm{~mm})$ & $l_{e}(\mathrm{~mm})$ & $\gamma$ \\
\hline T1-D1-L1 & 120 & 54 & 12 & 84 & 4.50 \\
\hline T2-D1-L1 & 30 & 14 & 12 & 84 & 1.17 \\
\hline T3-D1-L1 & 60 & 29 & 12 & 84 & 2.42 \\
\hline T4-D1-L1 & 90 & 44 & 12 & 84 & 3.67 \\
\hline T1-D2-L1 & 120 & 54 & 10 & 70 & 5.40 \\
\hline T1-D3-L1 & 120 & 54 & 14 & 98 & 3.86 \\
\hline T1-D4-L1 & 120 & 54 & 16 & 112 & 3.38 \\
\hline T1-D1-L2 & 120 & 54 & 12 & 60 & 4.50 \\
\hline T1-D1-L3 & 120 & 54 & 12 & 72 & 4.50 \\
\hline T1-D1-L4 & 120 & 54 & 12 & 96 & 4.50 \\
\hline
\end{tabular}

$D$ denotes the dowel diameter, $t$ denotes the thickness of the specimens, $t_{\mathrm{s}}$ denotes the thickness of the side members, $l_{e}$ denotes the end distance, and $\gamma$ denotes the thickness to diameter ratio.

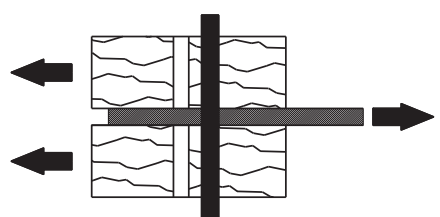

(a)

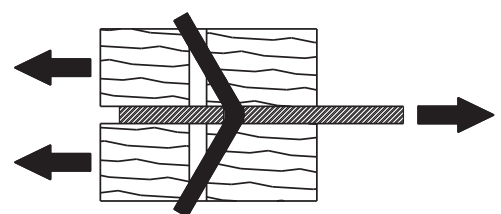

(b)

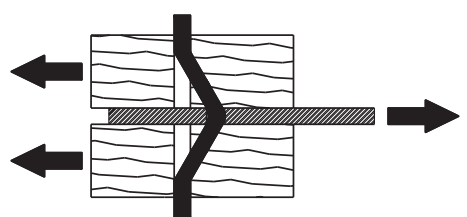

(c)

Figure 2: The yield modes of dowel-type fasteners in timber connections. (a) Mode I. (b) Mode II. (c) Mode III. 

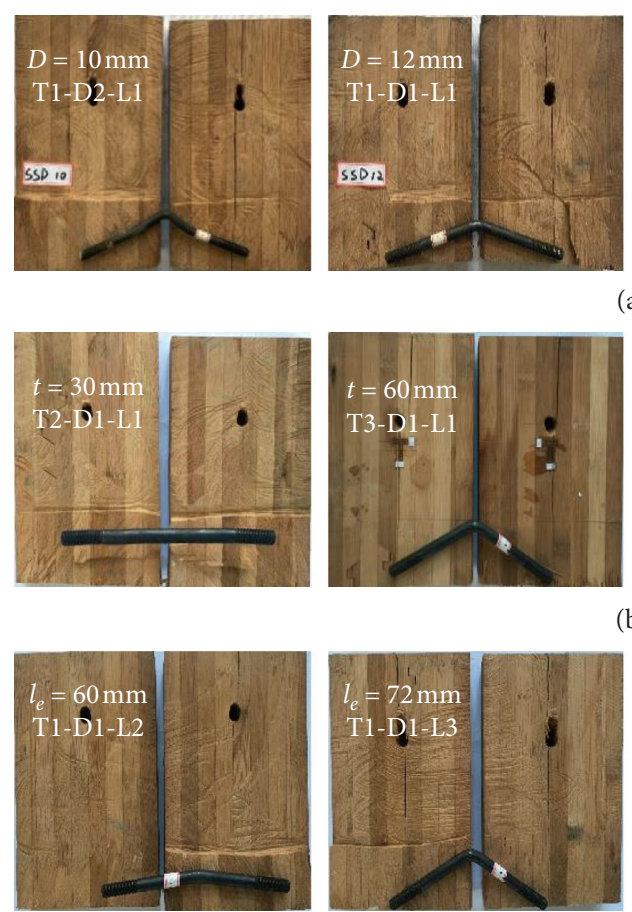

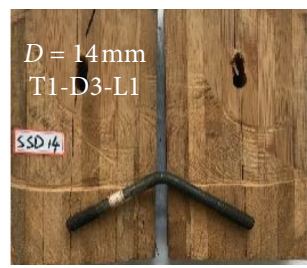

(a)

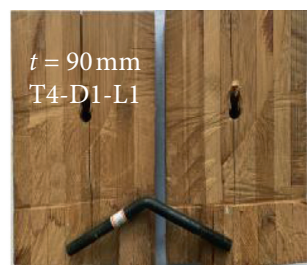

(b)
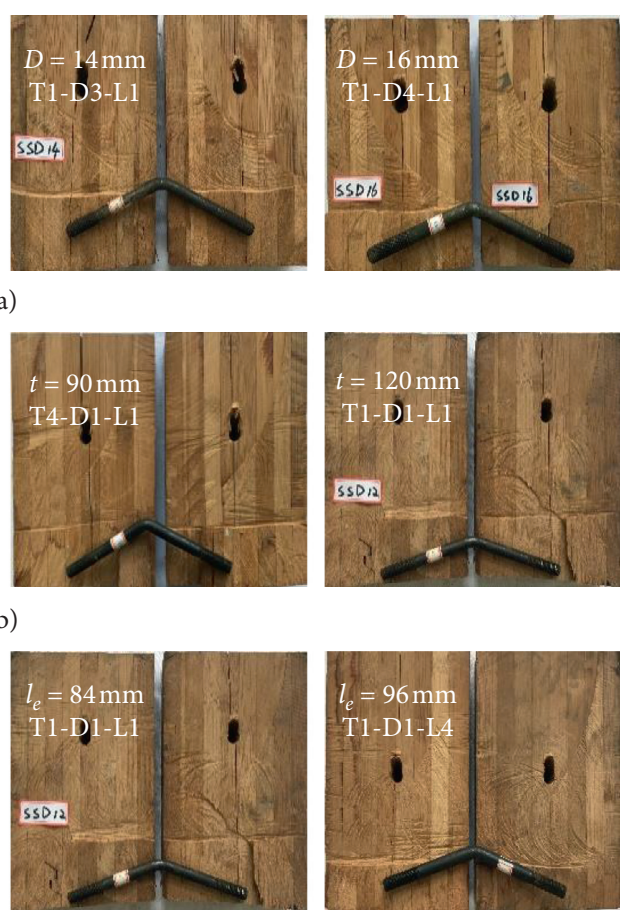

(c)

Figure 3: The yield and failure modes of the connections parallel to the grain. (a) Dowel diameter. (b) The thickness. (c) End distance.

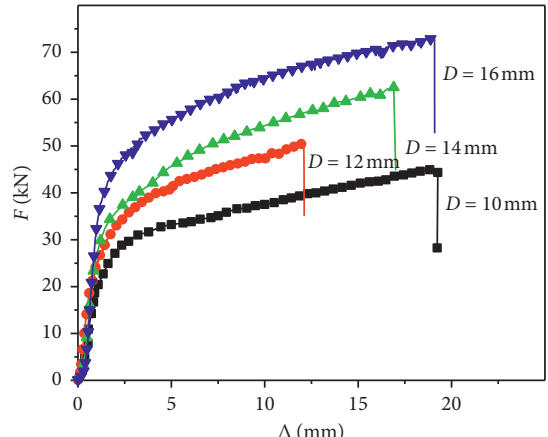

$\rightarrow$ T1-D1-L1 $\rightarrow$ T1-D3-L1

(a)

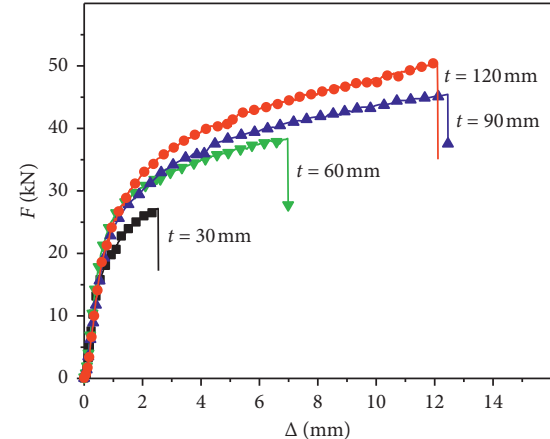

$\begin{array}{ll}\longrightarrow \text { T1-D1-L1 } \\ \rightarrow \text { T2-D1-L1 } & \rightarrow \text { T3-D1-L1 } \\ & \rightarrow \text { T4-D1-L1 }\end{array}$

(b)

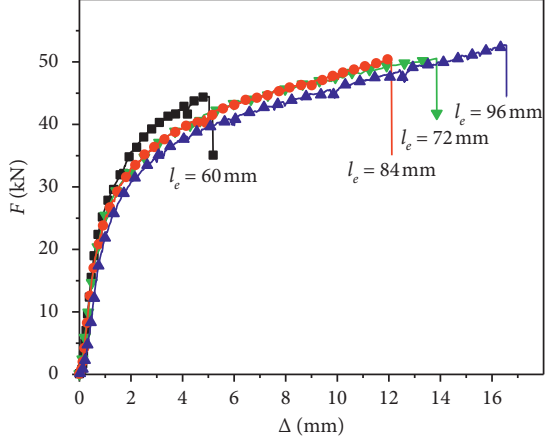

$\begin{array}{ll}\because \text { T1-D1-L1 } \\ \longrightarrow \text { T1-D1-L2 } & \longrightarrow \text { T1-D1-L3 } \\ & \longrightarrow \text { T1-D1-L4 }\end{array}$

(c)

Figure 4: The load-displacement curves of the connections. (a) Dowel diameter. (b) The thickness. (c) End distance.

TABLE 2: The test results of the connections in different groups.

\begin{tabular}{lccccccc}
\hline No. & $\gamma$ & $F_{y}(\mathrm{kN})$ & $\Delta_{\mathrm{y}}(\mathrm{mm})$ & $K_{1}(\mathrm{kN} / \mathrm{mm})$ & $F_{u}(\mathrm{kN})$ & $\Delta_{\mathrm{u}}(\mathrm{mm})$ & $K_{2}(\mathrm{kN} / \mathrm{mm})$ \\
\hline T1-D1-L1 & 4.50 & 32.33 & 1.17 & 43.56 & 50.56 & 12.05 & 4.77 \\
T2-D1-L1 & 1.17 & 23.40 & 1.26 & 28.78 & 27.15 & 2.49 & 2.65 \\
T3-D1-L1 & 2.42 & 25.66 & 1.40 & 34.45 & 38.33 & 6.96 & 3.42 \\
T4-D1-L1 & 3.67 & 30.15 & 1.44 & 38.76 & 45.48 & 12.46 & 5.16 \\
T1-D2-L1 & 5.40 & 28.89 & 1.98 & 29.56 & 45.08 & 19.00 & 3.95 \\
T1-D3-L1 & 3.86 & 39.56 & 1.86 & 44.42 & 62.49 & 16.90 & 8.97 \\
T1-D4-L1 & 3.38 & 48.56 & 2.54 & 53.28 & 72.98 & 18.98 & 3.80 \\
T1-D1-L2 & 4.50 & 30.26 & 1.36 & 38.14 & 44.45 & 5.03 & 3.09 \\
T1-D1-L3 & 4.50 & 32.16 & 1.26 & 45.56 & 50.83 & 13.32 & 3.21 \\
T1-D1-L4 & 4.50 & 33.88 & 1.39 & 44.28 & 52.82 & 16.53 & 4.81 \\
\hline
\end{tabular}


structures. This phenomenon proved that connections with sufficient end distance could guarantee the ductility of the connections.

\section{Calculation}

4.1. The Existing Calculation Methods. Regarding the loadcarrying capacity and yield resistance of the connections, different national standards of timber structure have different calculation methods. In Eurocode 5 [5], the three different equations were used to calculate the corresponding failure modes based on the Eurocode yield theory; and the characteristic load-carrying capacity of the connections can be obtained as the minimum value of the three equations. It can be expressed as follows:

$$
F_{u}=\min \begin{cases}f_{h, 1, k} t_{1} d, & \text { I, } \\ f_{h, 1, k} t_{1} d\left[\sqrt{2+\frac{4 M_{y, R K}}{f_{h, 1, k} d t_{1}^{2}}-1}\right], & \text { II, } \\ 2.3 \sqrt{M_{y, R K} f_{h, 1, k} d}, & \text { III, }\end{cases}
$$

where $F_{u}$ is the characteristic load-carrying capacity per shear plane per fastener, $\mathrm{kN}, f_{h, 1, \mathrm{k}}$ is the embedding strength of timber members, MPa, $t_{1}$ is the thickness of side member, $\mathrm{mm}, d$ is the dowel diameter, $\mathrm{mm}$, and $M_{y, R k}$ is the yield moment of the dowel, N.mm.

In Canadian engineering design in the wood [13], the yield resistance of the connections rather than bearing capacity was calculated according to different failure modes. Like Eurocode 5 , the minimum value of the connections was obtained to calculate the yield resistance. It can be expressed as follows:

$$
F_{y}=\min \begin{cases}\phi_{y} f_{1} \mathrm{~d} t_{1}, & \text { I, } \\ \phi_{y} f_{1} d^{2}\left(\sqrt{\left(f_{2} f_{y} / 6\left(f_{1}+f_{2}\right) f_{1}\right)+(t 1 / 5 d)}\right), & \text { II, } \\ \phi_{y} f_{1} d^{2} \sqrt{\frac{2 f_{2} f_{y}}{3\left(f_{1}+f_{2}\right) f_{1}}}, & \text { III, }\end{cases}
$$

where $F_{y}$ is yield resistance per shear plane per fastener, $\mathrm{kN}$, $f_{1}$ is the embedding strength of the side member, $\mathrm{MPa}, f_{2}$ is the embedding strength of the main member, $\mathrm{MPa}, t_{1}$ is the thickness of side member, $\mathrm{mm}, d$ is the dowel diameter, $\mathrm{mm}$, $f_{y}$ is the yield strength of the dowel, $\mathrm{MPa}$, and $\phi_{y}$ is resistance factor for yielding failure, 0.8. For the connection with slotted-in steel plate, $f_{2}$ can be calculated as

$$
f_{2}=K_{s p}\left(\frac{\phi_{\text {steel }}}{\phi_{Y}}\right) f_{u},
$$

where $K_{\mathrm{sp}}$ is the parameter, and the value of 3.0 is taken for mild steel; $\phi_{\text {steel }}$ is the resistance factor for steel plates in connections with dowels, 0.8 for mild steel, and $f_{u}$ is the specific tensile strength of steel, MPa.
4.2. The Equation for the Laminated Bamboo. The Eurocode yield theory is originated from Johansen theory of timber connection, which set the foundation for national standards of timber structure above. The basic assumptions of the theory are as follows: the failure mode of the connections is ductile and the embedding stress-strain relationship is the ideal rigid-plastic model. Then, based on the equilibrium condition of forces and three yield modes of fasteners, the equations to express the loadcarrying capacity of the connections can be determined. The stress distributions under three different yield modes in the rigid-plastic model are shown in Figure 6. The red circle denotes plastic hinge, $R$ is the load-carrying capacity per shear plane per fastener, $\mathrm{kN}, f_{e}$ is the embedding strength of timber members, $\mathrm{MPa}, t$ is the thickness of side member, $\mathrm{mm}$, and $M_{y}$ is the yield moment of the dowel, N.mm.

The following equations of the connections under three yield modes can be developed to calculate the load-carrying capacity:

$$
\begin{aligned}
R_{\mathrm{I}} & =f_{e} \mathrm{~d} t \\
R_{\mathrm{II}} & =f_{e} \mathrm{~d} t\left(\sqrt{2+\frac{4 M_{Y}}{f_{e} \mathrm{~d} t^{2}}-1}\right), \\
R_{\mathrm{III}} & =2 \sqrt{M_{y} f_{c} d} .
\end{aligned}
$$

Regarding the yield moment of the dowel, the calculation method is different in national standards of the timber structure. In Chinese timber structure design code [21], the yield moment of the dowel is related to the yield strength and the equation can be expressed as

$$
M_{y}=k_{w} W f_{y}
$$

where $k_{w}$ is the ratio of the plastic section modulus to the elastic section modulus, when the plastic behavior of the dowel is fully developed, 1.7, if not, 1.4. $W$ is the moment of section resistance in $\mathrm{mm}^{3} . F_{y}$ is the yield strength of the dowel in MPa.

In American design specification for wood construction, the yield moment is related to bending strength of the dowel. It can be determined based on the yield load of 5\% diameter deviation method or the average of the tensile strength and yield strength. Generally, it is taken as 1.3 times of yield strength. The equation can be expressed as

$$
M_{y}=0.22 f_{y} d^{3} \text {. }
$$

In Eurocode 5, the yield moment is related to tensile strength, and the equation can be expressed as

$$
M_{y}=0.22 f_{t} d^{2.6}
$$

where $f_{t}$ is the tensile strength of the bolt in MPa.

As mentioned before, M10, M12, M14, and M16 are tested and the yield moments are $72.30 \mathrm{kN} \mathrm{mm}, 167.70 \mathrm{kN} \mathrm{mm}$, $271.80 \mathrm{kN} \mathrm{mm}$, and $394.80 \mathrm{kN} \mathrm{mm}$, respectively. By comparison with different national standards, the results calculated in American code are the closest with experimental results; and the relative difference is less than $15 \%$. Next, equation (8) can be substituted into equations (5) and (6) to calculate the single- 

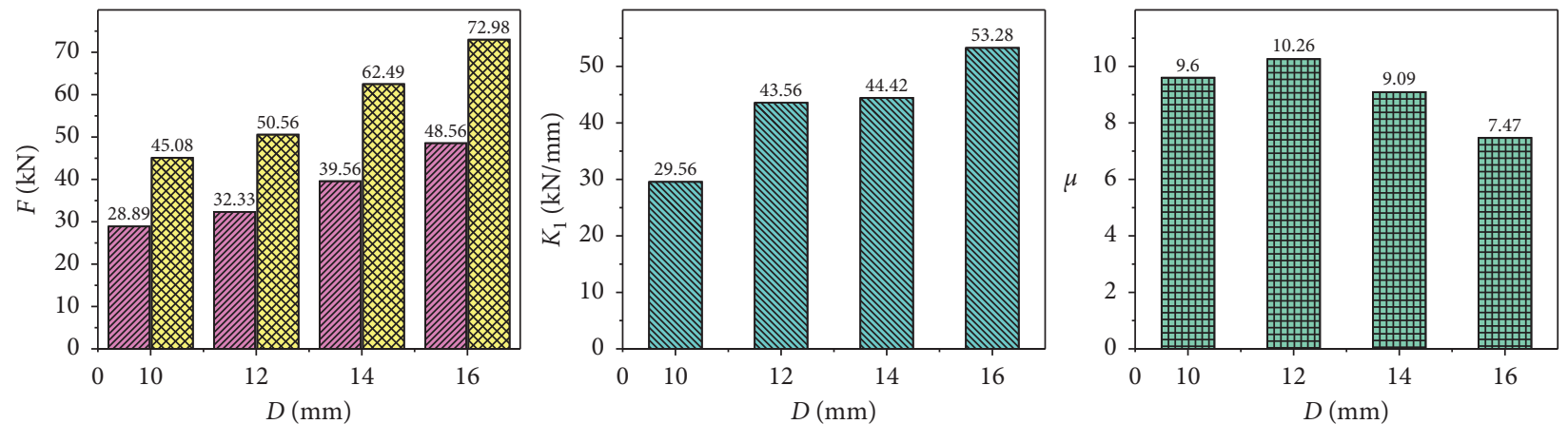

UIIA $F_{y}$

$F_{u}$

(a)
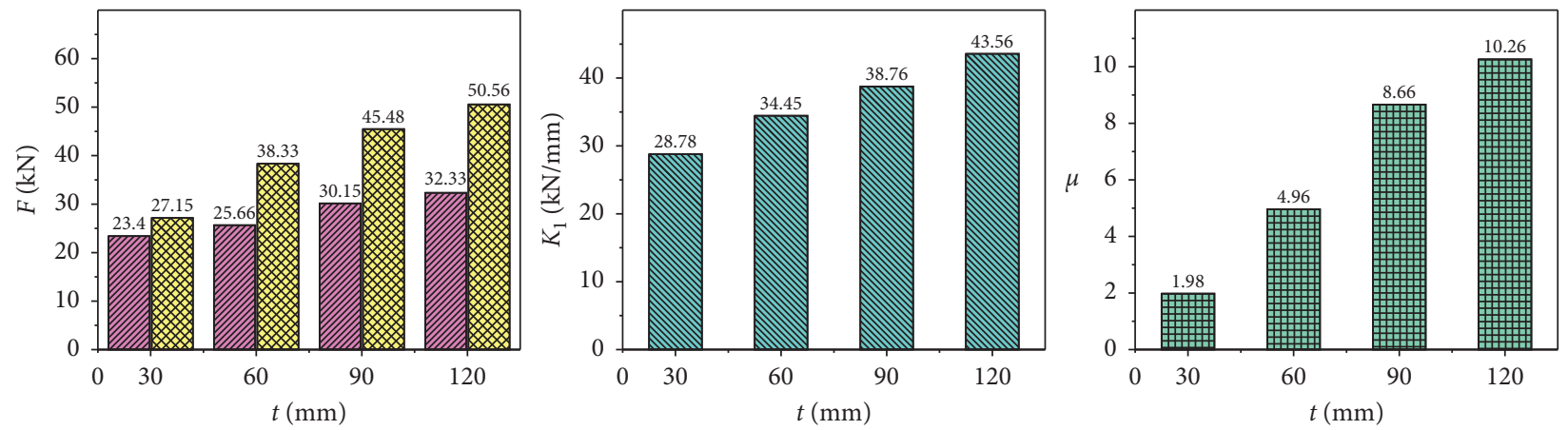

WIIA $F_{y}$

$F_{u}$

(b)
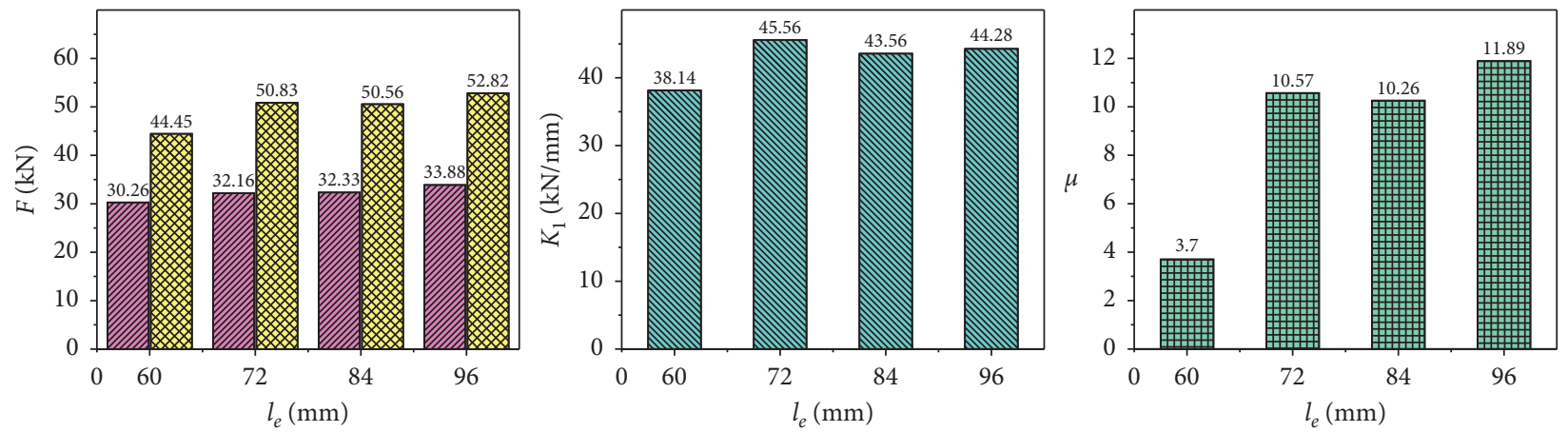

एIIA $F_{y}$

$F_{u}$

(c)

FIGURE 5: The effect of different factors on the mechanical parameters of the connections. (a) Dowel diameter. (b) The thickness. (c) End distance. 


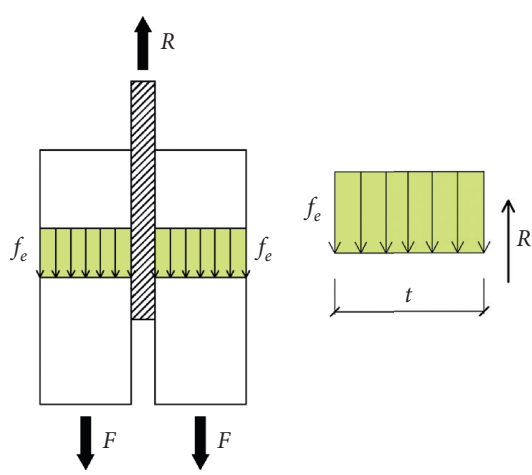

(a)

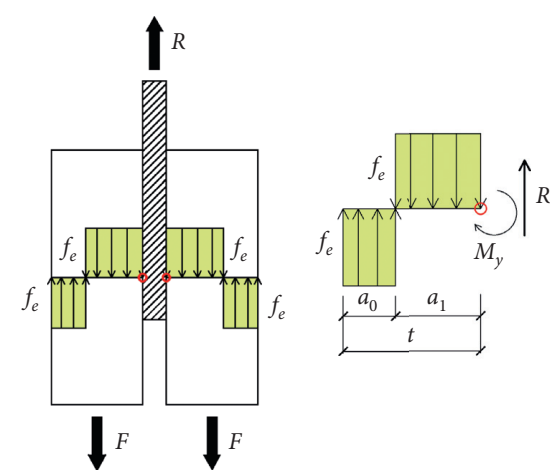

(b)

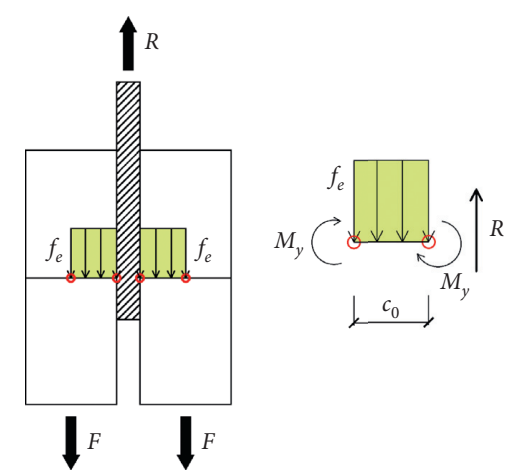

(c)

Figure 6: The stress distributions under three different yield modes. (a) Mode I. (b) Mode II. (c) Mode III.

shear bearing capacity of the connections. So, the equation can be expressed as

$$
R=\min \left\{\begin{array}{l}
f_{e} \mathrm{~d} t \\
f_{c} \mathrm{~d} t\left(\sqrt{2+\frac{0.88 f_{y} d^{2}}{f_{e} t^{2}}-1}\right), \\
0.94 d^{2} \sqrt{f_{y} f_{e}} .
\end{array}\right.
$$

According to three yield modes of boundary conditions, equation (10) can be further solved, which includes the thickness to diameter ratio interval. It can be shown in Figure 7. So, the upper and lower limits of Mode II are determined, and the equation can be expressed as

$$
R= \begin{cases}f_{e} \mathrm{~d} t, & \frac{t}{d} \leq 0.66 \sqrt{\frac{f_{Y}}{f_{e}}}, \\ f_{e} \mathrm{~d} t\left(\sqrt{2+\frac{0.88 f_{Y} d^{2}}{f_{e} t^{2}}-1}\right), & 0.66 \sqrt{\frac{f_{Y}}{f_{e}}} \leq \frac{t}{d} \leq 1.88 \sqrt{\frac{f_{Y}}{f_{c}}} \\ 0.94 d^{2} \sqrt{f_{Y} f_{c}}, & \frac{t}{d} \geq 1.88 \sqrt{\frac{f_{Y}}{f_{e}}}\end{cases}
$$

The dowel-bearing capacity of laminated bamboo is an essential parameter to evaluate the load-carrying capacity of this kind of connection. Previous tests and researches $[22,23]$ suggest that the dowel-bearing capacity of the laminated bamboo parallel to grain can be expressed as

$$
f_{e, \mathrm{par}}=(-0.0236 D+1.471) f_{c, o},
$$

where $f_{e}$, par and $f_{c, 0}$ stand for embedding strength and compressive strength of the laminated bamboo parallel to grain in $\mathrm{MPa}$, respectively.

Based on the above equations, the theoretical and experimental results of load-carrying capacity and failure modes are shown in Table 3. Compared with the ultimate load, the theoretical results are conservative but the predicted failure modes are accurate. In order to obtain an accurate solution of the load-carrying capacity of steel-tolaminated bamboo dowel connections with slotted-in steel plate, the formulas would need further discussion and optimized analysis. The modified coefficient $C_{g}$ can be introduced and combined with equation (11) to predict the load-carrying capacity of the connections. For further analysis, the modified coefficient $C_{g}$ is obtained to evaluate three yield modes. The corresponding values are 1.14 in Mode I, 1.08 in Mode II, and 1.50 in Mode III. When the connection occurs, Mode III, the modified coefficient is the largest. Through the previous analysis, when the end distance of the connections is 6 to 8 dowel diameters, they exhibit better ductility and bearing capacity. Plus, the effect of end distance on the bearing capacity of the connections is not considered in the calculation method. The sufficient end distance could guarantee the accuracy of the results and structural safety. It is noted that, considering the limited number of the connections, the modified coefficient 


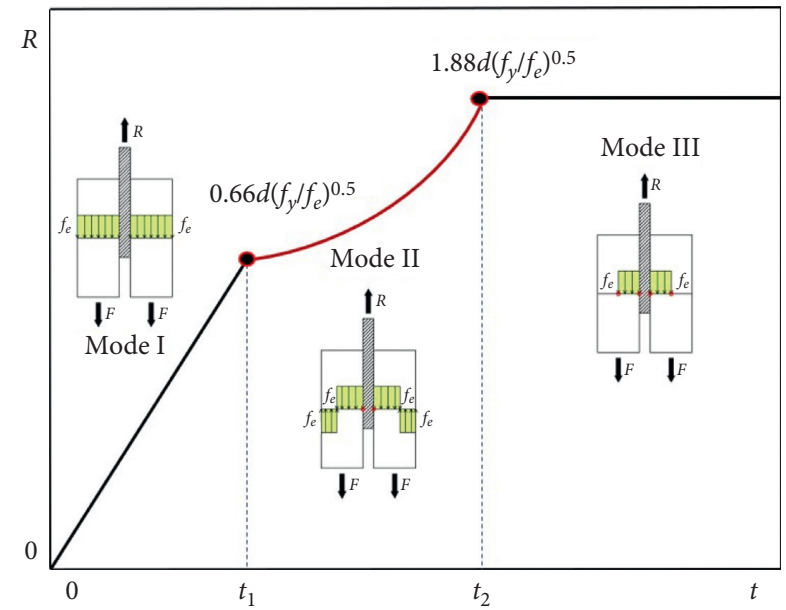

FIGURE 7: The boundary conditions of the load-carrying capacity of the connections.

TABle 3: The comparison of the load-carrying capacity of the connections.

\begin{tabular}{lccccc}
\hline \multirow{2}{*}{ No. } & \multicolumn{2}{c}{ Experimental results } & \multicolumn{3}{c}{ Theoretical results } \\
& $F_{u}(\mathrm{kN})$ & Yield mode & $R(\mathrm{kN})$ & Yield mode & $C_{g}$ \\
\hline T1-D1-L1 & 58.59 & II & 46.95 & II & 1.08 \\
T2-D1-L1 & 21.15 & I & 23.80 & I & 1.14 \\
T3-D1-L1 & 30.33 & II & 35.90 & II & 1.07 \\
T4-D1-L1 & 40.45 & II & 41.77 & II & 1.09 \\
T1-D2-L1 & 48.08 & III & 29.97 & III & 1.50 \\
T1-D3-L1 & 62.49 & II & 56.54 & II & 1.11 \\
T1-D4-L1 & 72.98 & II & 67.32 & II & 1.08 \\
\hline
\end{tabular}

suggested in the paper needs to be further verified. To sum up, the modified equation has better prediction and safety for the steel-to-laminated bamboo dowel connection with slotted-in steel plate.

\section{Conclusion}

The study investigated the load-carrying performance of one dowel-type steel-to-bamboo connection with a slotted-in steel plate. The effects of dowel diameter, thickness, and end distance on the yield load, the elastic stiffness, the ultimate load, the plastic stiffness, and the ductility rate of the connections have been studied. The following conclusions can be drawn:

(1) The typical load-displacement curves and yield modes of the connections parallel to the grain have been studied. The failure modes of side members are mainly shear failure and splitting failure, and they are accompanied by embedding failure. As for the dowel, the one-hinge yield mode has been witnessed the most.

(2) The influence of different factors on the load-carrying capacity of the connections has been analyzed as well. The dowel diameter significantly influences the yield and ultimate load and the initial stiffness. When the thickness of side members is in the range of $90-120 \mathrm{~mm}$, the thickness variation has no significant effect on yield load. As for the end distance, when it is in the range of $6 D-8 D$, the connections exhibit better ductility and embedding failure.

(3) Compared with experimental results, the theoretical results are conservative but the predicted failure modes are accurate. Further, the modified coefficient is introduced and combined with the theoretical equation to predict the load-carrying capacity of the connections, which has better prediction and safety for the steel-to-laminated bamboo dowel connection with slotted-in steel plate.

\section{Data Availability}

The data used to support the findings of this study are available from the corresponding author upon request.

\section{Conflicts of Interest}

The authors declare that they have no conflicts of interest.

\section{Acknowledgments}

This research was supported by the National Natural Science Foundation of China (NSFC) (51778299) and Open Fund of Shanghai Key Laboratory of Engineering Structure Safety (2019-KF05).

\section{References}

[1] A. Sinha, D. Way, and S. Mlasko, "Structural performance of glued laminated bamboo beams," Journal of Structural Engineering, vol. 140, no. 1, Article ID 04013021, 2013.

[2] Y. Xiao and J. Ma, "Fire simulation test and analysis of laminated bamboo frame building," Construction and Building Materials, vol. 34, no. 34, pp. 257-266, 2012.

[3] J. Fueyo, M. Dominguez, J. A. Cabezas et al., "Design of connections with metal dowel-type fasteners in double shear," Materials and Structures, vol. 42, no. 3, pp. 385-397, 2009.

[4] K. Johanson, "Theory of timber connections," International Association for Bridge and Structural Engineering, vol. 9, pp. 249-262, 1949.

[5] The European Standard EN 1995-1-1: 2004 (E), Eurocode 5: Design of Timber Structures-Part 1-1: General-Common Rules and Rules for Buildings, 2004.

[6] L. Daudeville, L. Davenne, and M. Yasumura, "Prediction of the load carrying capacity of bolted timber joints," Wood Science and Technology, vol. 33, no. 1, pp. 15-29, 1999.

[7] L. A. Soltis, F. K. Hubbard, and T. L. Wilkinson, "Bearing strength of bolted timber joints," Journal of Structural Engineering, vol. 112, no. 9, pp. 2141-2154, 1986.

[8] E. César, "Capacity Predictions for Bolted Timber Joints Failing by split-ting," The 10th World Connection Timber Engineering, Miyazaki, Tokyo, Japan, 2008.

[9] L. Doyle, Performance of Joints with Eight Bolts in Laminated Douglas-Fir (No. FSRN-FPL-10), Forest Products Lab Madison Wis., Madison, WI, USA, 1964.

[10] M. Patel and D. Hindman, "Comparison of single-and twobolted LVL perpendicular-to-grain connections. II: fracture 
models," Journal of Materials in Civil Engineering, vol. 24, no. 4, pp. 347-355, 2011.

[11] W. Mengjie, "Effect of humidity change on the performance of bolted joints of wood structural steel fillings," Master's thesis, Harbin Industrial University, Harbin, China, 2013.

[12] American Forest \& Paper Association, ANSI/AF\&PA NDS2012 National Design Specification for Wood Construction, AF\&PA, Washington, D.C., USA, 2012.

[13] Canadian Standard Association, O86-01, Engineering Design in Wood, Canadian Standard Association, Toronto, Canada, 2001.

[14] Z. Cui, M. Xu, Z. Chen et al., "Experimental study on bearing capacity of bolted steel-PSB-steel connections," Engineering Mechanics, vol. 36, no. 1, pp. 96-103, 2019, (In Chinese).

[15] J. H. P. Hover, "Load carrying capacity of multiple fastener steel to bamboo joints loaded parallel to the fibre direction," 2017.

[16] M. Xu, Z. Cui, L. Tu, Q. Xia, and Z. Chen, "The effect of elevated temperatures on the mechanical properties of laminated bamboo," Construction and Building Materials, vol. 226, pp. 32-43, 2019.

[17] Jg/T 199-2007, Testing Methods for Physical and Mechanical Properties of Bamboo Used in Building, Standards Press of China, Beijing, China, 2007.

[18] American Society for Testing and Materials, Standard Test Methods for Small Clear Specimens of Timber, American Society for Testing and Materials, West Conshohocken, PA, USA, 2014.

[19] American Society for Testing and Materials, Standard Test Method for Evaluating Dowel-Bearing Strength of Wood and Wood-Based Products, American Society for Testing and Materials, West Conshohocken, PA, USA, 2013.

[20] American Society for Testing and Materials, Standard Test Method for Single-Bolt Connections in Wood and Wood-Based Products, American Society for Testing and Materials, West Conshohocken, PA, USA, 2015.

[21] China Architecture Industry Press G. B. 50005-2003, Timber Structures Design Code, China Architecture Industry Press, Beijing, China, 2017.

[22] Z. Cui, L. Tu, M. Xu, Z. Chen, and C. Wang, "The evaluation of dowel-bearing properties of laminated bamboo parallel to grain," Structures, vol. 25, pp. 956-964, 2020.

[23] Z. Cui, M. Xu, L. Tu, Z. Chen, and B. Hui, "Determination of dowel-bearing strength of laminated bamboo at elevated temperatures," Journal of Building Engineering, vol. 30, Article ID 101258, 2020. 